\title{
Hizmet Sektöründe Psikolojik Güçlendirme, Duygusal Bağlılık ve Yapıcı Ses Çıkartma Davranışı Arasındaki İlişkilerin İncelenmesi
}

\section{Investigating Relationships Between Psychological Empowerment, Affective Commitment and Constructive Voice Behavior in the Service Sector}

\author{
Dr. Öğr. Üyesi Ülker ERDOĞAN ARACI \\ Batman Üniversitesi \\ Hasankeyf Meslek Yüksekokulu \\ E-posta: ulker.erdogan@batman.edu.tr
}

Öz

Bu araştırma, hizmet sektöründe psikolojik güçlendirme, duygusal bağlılık ve yapıcı ses çıkartma davranışı arasındaki ilişkilerin incelenmesi amacıyla yapılmıştır. Araştırma evrenini Kuzey Kıbrıs Türk Cumhuriyeti'nin (KKTC) Girne bölgesinde yer alan 5 yıldızlı otel işletmelerinin çalışanları oluşturmaktadır. Araştırma örneklemi ise, bu otellerin çeşitli departmanlarında görev yapan 211 çalışandan oluşmaktadır. Kolayda örnekleme yöntemi ile elde edilen veriler; açıklayıcı faktör analizi (AFA), güvenilirlik, korelasyon ve regresyon analizlerine tabi tutularak değerlendirilmiştir. Analiz sonucunda, psikolojik güçlendirmenin tüm alt boyutlarıyla duygusal bağlılık ve yapıcı ses çıkartma davranışına, duygusal bağlıığın ise yapıcı ses çıkartma davranışına pozitif yönde etki ettiği tespit edilmiştir.

Anahtar Kelimeler: Psikolojik Güçlendirme, Duygusal Bağlılık, Yapıcı Ses Çıkartma Davranışı, Hizmet Sektörü, Otel İşletmeleri.

\begin{abstract}
The purpose of this study is to investigate the relationship between psychological empowerment, affective commitment and constructive voice behavior in the service sector. The universe of the study consists of the employees of the 5-star hotel establishments located in the Kyrenia region of the Turkish Republic of Northern Cyprus. The sample of the study consists of 211 employees who work in various departments. Data which was collected by using convenience sampling was analysed through explanatory factor analysis (EFA), reliability, correlation and regression approach. As a result of the analysis, it has been determined that psychological empowerment (with all sub-dimensions) has a positive effect on affective commitment and constructive voice behavior and affective commitment has a positive effect on constructive voice behavior.
\end{abstract}

Key Words: Psychological Empowerment, Affective Commitment, Constructive Voice Behavior, Service Sector, Hotel Establishments. 


\section{Giriş}

İşletmelerin paydaşlarından biri olarak çalışanlar, müşteri ve işletme ilişkisine yön vermektedir. Süreç içerisinde çalışanların dolaylı ya da doğrudan etki ettikleri müşteri memnuniyeti ve işletme performansı gibi pek çok olgunun işletme lehine neticelenmesi, çalışanlar açısından sahip olunması gereken bazı önemli unsurlara dikkat çekilmesini gerektirmektedir. Turizmin yapısal özelliği gereği üretim ve tüketim faaliyetleri yoğunlukla eş zamanlı gerçekleşmektedir. Müşteri ve çalışan etkileşiminin yüzyüze olması turizm sektörü çalışanlarını, sarfettiği duygusal ve fiziksel emek bakımından diğer sektör çalışanlarından ayırmaktadır. Bu noktada çalışanın yapmış olduğu işe dair olumlu bir algıya sahip olması, beraberinde hem kendine hem de işletmeye etkili ve verimli çıktılar sağlayacaktır.

Çalışanın yaptığı işi anlamlı bulması ve kendini yetkin hissetmesi, çalışma sürecinde özerklik duygusuna sahip olması ve yaptığı işte etkili olduğuna inanması, örgütsel anlamda güçlü bir takım yaratmak, yönetsel anlamda da operasyonel süreç içerisinde yönetim fonksiyonlarının doğru işlemesini sağlamak adına kilit faktör olarak "psikolojik güçlendirme" olgusuna dikkat çekmektedir (Conger ve Kanungo, 1988; Thomas ve Velthouse, 1990; Spreitzer, 1995).

Çalışanın işiyle ilgili önerilerde bulunması, sorunların nasıl giderileceği ile ilgili fikirlerini ifade etmesi ve tasarladığı yeni veya daha etkili çalışma yöntemlerini paylaşması, gönüllülük esasına dayalı davranışlar olarak, dinamik ve etkili örgütsel yapıya ulaşma noktasında "çalışanın yapıcı ses çıkartma davranışı"nı ortaya çıkarmaktadır (Dyne ve diğ., 2003; Maynes ve Podsakoff, 2014).

Çalışanın işletmeye karşı güçlü bir aidiyet hissine sahip olması, kendini işletmede ailenin bir üyesi gibi görmesi, işletmedeki işini kendi kişisel işi olarak algılaması ve işletmede çalışıyor olmaktan gurur duyması gibi kendiliğinden çıkan çalışan ve işletme ilişkisinde tamamen içten aktif bir bağ şeklinde beliren tutumlar, örgütsel bağlılığın alt boyutlarından "duygusal bağıılık" boyutunu oluşturmaktadır (Meyer ve Allen, 1997; Wasti, 2005).

Güçlendirilmiş hizmet çalışanlarının, iş sürecinin her aşamasına yansıyabilecek işe dair psikolojik açıdan oluşmuş olan olumlu algıları, işletme ile kuracakları duygusal bağı arttırabilmektedir. İşletmesi ile ilişkisinde güçlü bir duygusal bağa sahip çalışanlarda da, işe dair yapıcı önerilerde bulunma isteği oluşabilmektedir (Fuller ve diğ., 2006; Liang ve diğ., 2012; Raub ve Robert, 2010; Spreitzer, 1995).

Bu bilgiler doğrultusunda mevcut çalışmada öncelikle; psikolojik güçlendirme, yapıcı ses çıkartma davranışı ve duygusal bağlıık ile ilgili alanyazın taraması yapılmış, değişkenler arasındaki ilişkiler incelenmiş ve hipotezler belirlenmiştir. Elde edilen veriler doğrultusunda 1) psikolojik güçlendirmenin duygusal bağlılığa etkisi 2) psikolojik güçlendirmenin yapıcı ses çıkartma davranışına etkisi 3) duygusal bağııı̆̆ın yapıcı ses çıkartma davranışına etkisi incelenmiştir.

\section{Alanyazın Taraması}

\subsection{Psikolojik Güçlendirme}

Psikolojik güçlendirme olgusunun temeli, Bandura (1977) tarafından sosyal bilişsel teori kapsamında ortaya konan özyeterlilik kavramı ile oluşturulmuştur. Olgunun öncüllerinden olan Conger ve Kanungo (1988), özyeterlilikten yoksun çalışanlar ile 
güçlendirilmiş yönetimsel uygulamalardan etkili çıktıların sağlanamayacağından bahsetmektedir. Örgütsel yapı içerisinde astların kendilerini güçsüz hissetmeleri durumunda, güçsüzlük durumunu ortaya çıkaran şartların incelenmesi önemlidir. Bu noktada Conger ve Kanungo (1988), güçsüzlüğe sebep olan dışsal unsurların ortadan kaldırımasının yanında, tüm strateji ve taktiklerin doğrudan astların özyeterlilik duygusunu arttıracak şekilde yapılandırılmasına değinmektedir. İlgili süreçte, Thomas ve Velthouse (1990), güçlendirme olgusunu, bilişsel açıdan genişletmiştir. Çalışanın işe dair rolüne ve görev sorumluluğuna atıf yapılan modelde, psikolojik güçlendirme içsel görev motivasyonu olarak tanımlanmakta ve dört bilişsel boyuttan oluşmaktadır. Spreitzer (1995) ise, Thomas ve Velthouse (1990) tarafından genişletilen çalışmadan yararlanarak, dört bilişsel boyutu temel alan psikolojik güçlendirme ölçeğini oluşturmuş ve ölçmüştür.

Psikolojik güçlendirme değişkeninin boyutlarından biri olarak anlam; çalışanın yaptığı işi anlamlı ve önemli hissetme duygusu, yetkinlik; özyeterlilik olarak da ifade edilebilen veya çalışanın görevini başarılı bir şekilde yerine getirebilme yeteneğine olan inancı, özerklik; çalışanın yaptığı işle ilgili kendi kendine kararlar alabilecek özgürlüğe sahip olması, etki ise çalışanın iş sürecinde bölümündeki olaylar üzerinde etkisinin olduğuna dair inancı olarak ifade edilmektedir (Spreitzer, 1995).

Psikolojik açıdan güçlendirilmiş çalışanlar, işletme içerisinde aktif olarak katılım göstermektedir. Yaptığı işi psikolojik açıdan güçlü bir şekilde sahiplenen çalışanlar, çalışma ortamında daha fazla verimlilik sağlamaktadır (Sigler ve Pearson, 2000). Aynı zamanda kendine inanan güçlü çalışanların organizasyon içerisinde önemli ve etkili olduklarını hissetmesi, işletmeye karşı olan bağlılık duyguları arttırmaktadır (Kark, Shamir ve Chen, 2003). Buna karşılık işletme içerisinde etkili olmadığına ya da daha az etkili olduğuna dair hisse sahip olan çalışanın, operasyonel süreç içerisinde işletme performansına katkısının düşük olacağından bahsedilmektedir (Taylor, 2013).

\subsection{Duygusal Bağlılık}

Örgütsel bağlılık; duygusal bağlılık, devam bağlıığı ve normatif bağlılık olmak üzere üç temel bileşenden oluşmaktadır. Bu üç bileşen, çalışanları işletmeye bağlayan psikolojik bir durumu yansıtmakla birlikte, çalışanların işletmeleri ile olan ilişkisini sürdürme ya da sonlandırma kararlarına etki eden bir olgu olarak değerlendirilmektedir. Buna göre çalışanın işletme ile gönülden bağ kurmasına vurgu yapan duygusal bağlılık, çalışanın işletme ile özdeşleşmesini ve oraya dahil olma istekliliğini ifade etmektedir. Devam bağlıı̆ı, işletmeden ayrılma durumunda katlanılmak durumunda kalınacak maliyetlerin farkındalığı ve ihtiyaçlar dolayısıyla işletmede kalmaya devam edilmesidir. Normatif bağlılık ise işletmede kalmanın bir zorunluluk olarak görülmesi ve neticesinde işletmede kalınması gerekliliğinin düşünülmesi şeklinde tanımlanmaktadır (Allen ve Meyer, 1990; Meyer ve Allen, 1991).

Bu çalışmada, örgütsel bağlılık değişkeninin "duygusal bağlılık" boyutu ele alınmaktadır. Örgütsel bağlılığın en önemli boyutu olan duygusal bağlılık (Cohen, 2003; Kehoe ve Wright 2013), çalışanın işletmeye karşı güçlü bir inanca sahip olmasına, işletmenin hedef ve değerlerini kabul etmesine ve pek çok açıdan işletme için çaba göstermeye istekli olmasına vurgu yapmaktadır (Agarwal, DeCarlo ve Vyas, 1999).

Duygusal bağlılık, çalışanların işletmedeki işini kendi kişisel işi olarak algılaması gibi işletme için pek çok açıdan olumlu çıktılara vesile olmaktadır. Alanyazında duygusal bağlıı̆̆ı güçlü çalışanların, iş tatminlerinin ve iş performanslarının 
artacağından, işe devamsızlık davranışlarının ve işten ayrılma niyetlerinin azalacağından ya da daha fazla örgütsel vatandaşlık davranışı sergileyeceklerinden bahsedilmektedir (Akdemir ve Duman, 2016; Meyer ve diğ., 2002).

\subsection{Yapıcı Ses Çıkartma Davranışı}

Hizmet çalışanlarının işle ilgili davranışları hem girdi hem de çıktı olarak değerlendirilebilir. Duygusal ve fiziksel emeğin yoğun olarak sarfedildiği turizm sektöründe, üretim ve tüketimin genellikle aynı anda gerçekleşmesi dolayısıyla çalışanların bütünsel bir şekilde deneyimledikleri iş süreçleri, çalışanlara işin daha verimli ve etkili nasıl ortaya konulacağıyla ilgili olarak önemli kazanımlar sağlamaktadır. Elde edilen bu kazanımlar, çalışanların işe ve işletmeye dair yapıcı fikir, öneri ve görüşlere sahip olmalarına vesile olmaktadır. Bu noktada çalışanın yapıcı ses çıkartma davranışı dikkat çekmektedir.

Çalışanın yapıcı ses çıkartma davranışı, işlerin daha etkili ve verimli bir şekilde ortaya konulması adına, işletmeye yapıcı katkılar sunan ifadeleri içermektedir. Fikirlerin isteğe bağlı aktarımı olarak işle ilgili konular hakkında öneri, endişe ve görüşlerin bildirimi şeklinde nitelendirilen yapıcı ses çıkartma davranışı, var olan iş uygulamaları ve prosedürlerine öneriler getirmesi, yeni veya daha iyi yöntemlere dikkat çekmesiyle, yönetimin ele alması gereken kritik konularda örgütsel işlevsellik üzerinde olumlu etki yaratmaktadır (LePine ve Van Dyne, 1998; Maynes ve Podsakoff, 2014; Morrison, 2011).

Çalışanın bütünsel anlamda işi ile sağladığı katkının değerli olduğunu algılaması önemlidir. Çalışanın işe ve işyerine dair algısı, olumlu tutum ve davranışların ortaya çıkarılması sürecine etki etmektedir. Çalışanlar çalışma ortamını, görüş, fikir ve önerilerin paylaşılabileceği bir yer olarak hissettiklerinde, hem daha çok yapıcı ses çıkartma davranışında bulunacak hem de işlerine daha çok bağlanacaklardır (Rees, Alfes ve Gatenby, 2013; Farndale ve diğ., 2011).

\subsection{Psikolojik Güçlendirme, Duygusal Bağlılık ve Yapıcı Ses Çıkartma Davranışı İlişkisi}

Psikolojik güçlendirme, içsel bir motivasyon faktörü olarak, pozitif bireysel ve örgütsel çıktıları geliştirme potansiyeline sahip dört bilişsel unsurdan oluşmaktadır (Spreitzer, 1996). Stander ve Rothmann (2010) psikolojik güçlendirmeden, bireyin iş yerindeki içsel motivasyonunun bir göstergesi olarak işe adanmışlığının öncülü olarak bahsetmektedir. Çalışanlar işlerini değerli bulduklarında (anlam), işlerini kendi kendilerine gerçekleştirdiklerinde (özerklik), işlerini yapabilme becerisine sahip olduklarında (yeterlilik) ve iş sürecine katkı sağladıklarını hissettiklerinde (etki) yüksek düzeyde örgütsel bağlılık yaşayabilmektedir (Macsinga ve diğ., 2015). Karakaş ve Serçek (2014), Işık ve Yasım (2017) tarafından Türkiye'de otel çalışanları üzerinde, Jha (2011) tarafından Hindistan'da bilişim sektörü çalışanları üzerinde Hashmi ve Naqvi (2012) tarafından Pakistan'da banka çalışanları üzerinde, Ouyang ve diğ., (2015) tarafından Çin'de hastane çalışanları üzerinde, Abdullah ve diğ., (2015) tarafından Malezya'da eğitim sektörü çalışanları üzerinde gerçekleştirilen çalışmalarda, psikolojik güçlendirmenin tüm alt boyutlarıyla birlikte duygusal bağlılığa pozitif yönde etki ettiği tespit edilmiştir. Alan yazından elde edilen bilgilerden hareketle, psikolojik güçlendirme (alt boyutları ile birlikte) ile duygusal bağlılık arasındaki ilişkiye yönelik oluşturulan hipotez aşağıdaki şekildedir: 
$H_{1}$ : Çalışanların psikolojik güçlendirme algıları duygusal bağlııklarını pozitif yönde etkiler. etkiler.

$\mathrm{H}_{1 \mathrm{a}}$ : Psikolojik güçlendirmenin anlamlılık boyutu duygusal bağlıı̆ı pozitif yönde etkiler.

$H_{1 b}$ : Psikolojik güçlendirmenin yetkinlik boyutu duygusal bağlıı̆̆ pozitif yönde etkiler.

$\mathrm{H}_{1 \mathrm{c}}$ : Psikolojik güçlendirmenin özerklik boyutu duygusal bağlıı̆̆ı pozitif yönde

$H_{1 d}$ : Psikolojik güçlendirmenin etki boyutu duygusal bağııı̆̆ı pozitif yönde etkiler.

Alan yazında pek çok araştırma, çalışanların psikolojik güçlendirme algılarının, yapıcı ses çıkartma davranışlarını ortaya çıkaracağından bahsetmektedir (Frazier ve Fainshmidt, 2012; Tangirala ve Ramanujam, 2012; Wang ve diğ., 2016). Raub ve Robert (2012) tarafından Orta Doğu ve Asya Pasifik bölgelerinde bulunan zincir otel işletmelerinde görev yapan ön hizmet çalışanları $(n=640)$ üzerinde gerçekleştirilen bir araştırmada, psikolojik güçlendirme ile yapıcı ses çıkartma davranışı arasında güçlü bir ilişki olduğu ortaya konmuştur. Alan yazından elde edilen bilgilerden hareketle, psikolojik güçlendirme (alt boyutları ile birlikte) ile yapıcı ses çıkartma davranışı arasındaki ilişkiye yönelik geliştirilen hipotez aşağıdaki şekilde ifade edilebilir.

$H_{2}$ : Çalışanların psikolojik güçlendirme algıları yapıcı ses çıkartma davranışlarını pozitif yönde etkiler.

$\mathrm{H}_{2 a}$ : Psikolojik güçlendirmenin anlamlılık boyutu yapıcı ses çıkartma davranışını pozitif yönde etkiler.

$\mathrm{H}_{2 b}$ : Psikolojik güçlendirmenin yetkinlik boyutu yapıcı ses çıkartma davranışını pozitif yönde etkiler.

$\mathrm{H}_{2 c}$ : Psikolojik güçlendirmenin özerklik boyutu yapıcı ses çıkartma davranışını pozitif yönde etkiler.

$\mathrm{H}_{2 d}$ : Psikolojik güçlendirmenin etki boyutu yapıcı ses çıkartma davranışını pozitif yönde etkiler.

Duygusal bağlıık, hizmet sektörü çalışanları için işletme lehine önemli çıktılara vesile olabilecek bir faktör olarak değerlendirilebilir. Örgüte karşı güçlü bir duygusal bağa sahip olan çalışanın, iş sürecinin her aşamasına katkı sağlama isteğinde bulunacağı yadsınamaz bir gerçek olarak gözükmektedir (Meyer ve diğ., 2002, Purcell, 2014). Lapointe ve Vandenberghe (2018) tarafından Kanada'da müşteri hizmetleri çalışanları üzerinde gerçekleştirilen bir çalışmada, duygusal bağlıı̆̆ın yapıcı ses çıkartma davranışını pozitif yönde etkilediği tespit edilmiştir. Elde edilen bilgiler doğrultusunda, duygusal bağlııı ile yapıcı ses çıkartma davranışına yönelik geliştirilen hipotez aşağıdaki şekildedir.

$H_{3}$ : Çalışanların duygusal bağlııkları yapıcı ses çıkartma davranışlarını pozitif yönde etkiler

Bu araştırmada, hizmet sektöründe çalışanların psikolojik güçlendirme algılarının tüm alt boyutları ile duygusal bağlılıklarını ve yapıcı ses çıkartma davranışlarını pozitif yönde etkilediği ve bununla birlikte duygusal bağlılıklarının yapıcı ses çıkartma davranışlarını pozitif yönde etkilediği varsayılmaktadır. 


\section{Araştırmanın Yöntemi}

\subsection{Evren ve Örneklem}

Araştırma evrenini, Kuzey Kıbrıs Türk Cumhuriyeti'nin (KKTC) Girne bölgesinde yer alan 5 yıldızlı otel işletmelerinin çalışanları oluşturmaktadır. KKTC Turizm planlama dairesinden alınan veriler doğrultusunda, Girne bölgesinde toplam 14 adet beş yıldızlı otel işletmesi tespit edilmiştir. Araştırma evrenini oluşturan otellerin insan kaynakları müdürleriyle görüşülmüş fakat toplam çalışan sayısı bilgisine ulaşılamamıştır. $\mathrm{Bu}$ sebeple literatürde önerilen örneklem büyüklüğü kriterleri dikkate alınmıştır. Buna göre, bazı araştırmacılar örneklem büyüklüğünün en az 200 olması gerektiğini belirtirken, bazı araştırmacılar ise çalışmada kullanılan gözlenen değişken sayısının on katı olması gerektiğini ifade etmektedir (Hair ve diğ., 1998; Hair ve diğ., 2011; Kline, 2011). Araştırmada kullanılan gözlenen değişken sayısı 25 olduğundan, bu sayının on katı olan 250 sayısı en az örneklem büyüklüğü olarak belirlenmiştir. Kaynak ve zaman kısıtlığı sebebiyle, kolayda örnekleme yöntemi ile kolay ulaşılabilen ve araştırmaya katılmaya gönüllü olan 300 kişiye anket dağıtılmıştır. Anket formu 2018 Ekim ve Kasım aylarında tüm işletmelere yaklaşık olarak eşit bir sayıda uygulanmıştır. 240 adet geri toplanan anket içerisinden 211 anket çalışmaya dahil edilmiş, 29 anketin geçerliliği yeterli görülmemiştir.

\subsection{Veri Toplama Aracı}

Araştırmada veri toplama aracı olarak anket kullanılmıştır. Anket formu dört bölümden oluşmaktadır. Birinci bölümde psikolojik güçlendirme, ikinci bölümde duygusal bağlılık, üçüncü bölümde çalışanın yapıcı ses çıkartma davranışı son bölümde ise çalışanların demografik bilgilerine ilişkin sorulara yer verilmiştir. Çalışmada kullanılan ölçekler, önceki çalışmalardan adapte edilmiştir. Çalışmanın anketi 5'li Likert şeklinde (1=Kesinlikle katılmıyorum, 5=Kesinlikle katılıyorum) derecelendirilmiştir.

Psikolojik güçlendirmeyi ölçmek için Spreitzer'ın (1995) güçlendirme ölçeği kullanılmıştır. Anlam, yetkinlik, özerklik ve etki olmak üzere dört faktörden oluşan ölçek toplam 12 madde içermektedir. Duygusal bağlılığı ölçmek için Allen ve Meyer (1990)'ın üç boyutlu örgütsel bağlılık öçeği (duygusal, devamlılık ve normatif bağlılık) esas alınarak Akdemir ve Çalış Duman (2016) tarafından geliştirilen, sekiz maddeden oluşan duygusal bağlılık ölçeği kullanılmıştır. Çalışanın yapıcı ses çıkartma davranışını ölçmek amacıyla Maynes ve Podsakoff (2014)'ün dört boyutlu ses çıkartma davranışı ölçeği (destekleyici, yapıcı, savunmacı ve yıkıcı ses) esas alınarak, 5 maddeden oluşan yapıcı ses çıkartma davranışı ölçeği kullanılmıştır.

\subsection{Veri Analizi}

Araştırmanın istatistiksel analizi SPSS 23.0 programı kullanılarak gerçekleştirilmiştir. Araştırmanın verileri; açıklayıcı faktör analizi (AFA), güvenilirlik, korelasyon ve regresyon analizlerine tabi tutularak değerlendirilmiştir. Belirtilen analizler öncesi, araştırma setinin normal dağılıma uygunluğu basıklık (kurtosis) ve çarpıklık (skewness) değerleri baz alınarak incelenmiştir. Tespit edilen katsayılar psikolojik güçlendirme için ,306 ile -,500; duygusal bağlılık için ,581 ile -,866; yapıcı ses çıkartma davranışı için ,-657 ile -,068 oranlarında bulunmuştur. İlgili katsayılara bağlı olarak araştırma verilerinin normal dağılım gösterdiği $(+1,5 /-1,5)$ söylenebilir (Tabachnick and Fidell, 2013). 


\section{Bulgular}

\subsection{Demografik Bulgular}

Araştırmanın \%51.2'sini erkek \% 47.9'unu kadın çalışanlar oluşturmaktadır. Araştırmaya katılanların \%74,9'u 18 ile 30 yaş aralığındadır. Katılımcıların \%32,7'si üniversite, \%31,3'ü ise lise mezunudur. Katılımcıların bulunduğu işletmedeki deneyimlerine bakıldığında \%54'ü 1-2 yıl, \% 19,5'i ise 4 ve üstü yıl aralığında aynı işletmede çalışmaktadır. Katılımcıların turizm sektöründeki çalışma deneyimleri incelendiğinde \%47,9'u4 ve üstü, \%28'i ise 1-2 yıl aralığında deneyime sahiptir. Araştırmanın \%53,6'sını yiyecek içecek departmanı, \%14.7'sini mutfak, \%12.3'ünü satın alma, \%10.9'unu güvenlik ve \%8.5'ini ise kat hizmetleri departmanı çalışanları oluşturmaktadır.

\subsection{Faktör Analizi ve Güvenilirlik Analizi}

Araştırmada kullanılan psikolojik güçlendirme, duygusal bağlılık ve yapıcı ses çıkartma davranışı ölçeklerinin güvenilirlik analizi sonuçları, kabul edilebilir sınır olan \%70'in üzerindedir. Tespit edilen değerler Tablo 1'de gösterilmektedir. İlgili ölçekleri oluşturan değişkenlerin teorik olarak öngörülen faktör bileşenlerine ayrılıp ayrılmadığını tespit etmek üzere keşifsel faktör analizi yapılmıştır. Ortaya çıkan sonuçlar Tablo 2'de gösterilmektedir.

Tablo 1: Güvenilirlik Analizi

\begin{tabular}{llll}
\hline Ölçek & Madde Sayısı & Cronbach Alpha \\
\hline Psikolojik Güçlendirme & 12 & $.89,2$ \\
Anlamlıık & 3 & $.90,4$ \\
Yetkinlik & 3 & $.80,2$ \\
Özerklik-Etki & 6 & $.90,6$ \\
• Duygusal Bağlılık & 8 & $.91,8$ \\
• Yapıcı Ses Çıkartma Davranışı & 5 & $.86,6$
\end{tabular}

Faktör analizinde temel bileşenler analizi ve direct oblimin döndürme yöntemi kullanıımıştır. Araştırmada kullanılan psikolojik güçlendirme ölçeğinin faktör analizi sonucunda, anlam, yetkinlik, özerklik ve etki olmak üzere 4 boyuttan oluşan orjinal ölçek, 3 boyut altında toplanmıştır. Anlam ve yetkinlik boyutlarına ilişkin maddeler kendi boyutları altında toplanmış fakat özerklik ve etki boyutları birleşerek tek faktör altında toplanmıştır (Tablo 2). Faktör sonuçlarına göre ölçeğin toplam varyansı açıklama oranı \%74.553'tür. Kaiser-Meyer-Olkin (KMO) değeri 0,858 ve Bartlett testi sonucu $\left(x^{2}{ }_{(66)}=1647,078 ; p<0,001\right)$ ise anlamlıdır. Gerçekleştirilen güvenilirlik analizinde ise, ölçeğin toplam güvenilirliğinin yüksek olduğu tespit edilmiştir (Tablo 1). 
Tablo 2: Öıçeklere İlişkin Açıklayıcı Faktör Analizi Sonuçları

\begin{tabular}{cccc}
\hline \multicolumn{1}{c}{ Faktör(ler) } & $\begin{array}{c}\text { Madde } \\
\text { Sayısı }\end{array}$ & $\begin{array}{c}\text { Faktör Yük } \\
\text { Aralığı }\end{array}$ & Açıklanan Varyans (\%) \\
\hline Psikolojik Güçlendirme & 12 &, $956-, 626$ & 74,553 \\
1. Özerklik-Etki & 6 &, $924-, 735$ & 46,989 \\
2. Anlamlılık & 3 &, $956-, 854$ & 64,070 \\
3. Yetkinlik & 3 &, $925-, 626$ & 74,553
\end{tabular}

Kaiser-Meyer-Olkin: ,858 Bartlett: ki-kare=1647,078; $d f=66 ; p=, 000$

\section{Duygusal Bağlılık Ölçeği}

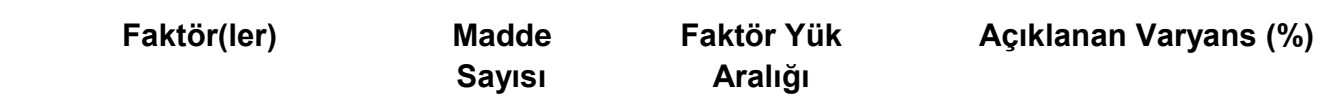

Duygusal Bağlılık

8

, $874-, 566$

64,537

Kaiser-Meyer-Olkin: ,893 Bartlett: ki-kare=1189,721; df=28; $p=, 000$

Yapıcı Ses Çıkartma Davranışı Ölçeği

$\begin{array}{cccc}\text { Faktör(ler) } & \begin{array}{c}\text { Madde } \\ \text { Sayısı }\end{array} & \begin{array}{c}\text { Faktör Yük } \\ \text { Aralığı }\end{array} & \text { Açıklanan Varyans }\end{array}$

\begin{tabular}{lllll}
\hline $\begin{array}{l}\text { Yapıcı Ses } \\
\text { Davranışı }\end{array}$ & Çırtma & 5 &, $860-, 744$ & 65,677 \\
\end{tabular}

Kaiser-Meyer-Olkin: ,821 Bartlett: ki-kare=526,170; $d f=10 ; p=, 000$

Sekiz maddeli duygusal bağlılık ölçeği için yapılan faktör analizinde (Tablo 2) ölçek, toplam varyansın \% 64,537'sini açıklamaktadır. KMO değeri 0,893 ve Bartlett testi sonucu $\left(\mathrm{x}^{2}{ }_{(28)}=1189,721 ; \mathrm{p}<0,001\right)$ anlamlı olarak hesaplanmıştır. Güvenilirlik analizi sonucu ise, ölçeğin yeterli güvenilirliğe sahip olduğunu ortaya koymaktadır (Tablo 1).

Beş maddeli yapıcı ses çıkartma davranışı ölçeği için gerçekleştirilen faktör analizinde (Tablo 2) tek faktörlü yapı, toplam varyansın \%65,677'sini açıklamaktadır. KMO değeri 0,821 ve Bartlett testi sonucu $\left(x_{(10)}^{2}=526,170 ; p<0,001\right)$ ise anlamlıdır. Güvenilirlik analizi sonucunda ise ölçeğin yüksek bir güvenilirliğe sahip olduğu belirlenmiştir (Tablo 1). 


\subsection{Pearson Korelasyon Analizi}

Araştırma kapsamında, psikolojik güçlendirme alt boyutları ile duygusal bağlılık ve yapıcı ses çıkartma davranışı arasındaki ilişki pearson korelasyon analizi ile test edilmiştir. Ortalama, standart sapma ve korelasyon değerleri Tablo 3'te gösterilmektedir.

Tablo 3: Pearson Korelayon Analizi Sonuçları

\begin{tabular}{|c|c|c|c|c|c|c|c|}
\hline Değişkenler & Ort. & S.S. & 1 & 2 & 3 & 4 & 5 \\
\hline 1.Anlam & 4,15 & ,80 & 1 & & & & \\
\hline 2.Yetkinlik & 4,09 & ,70 &, $466^{* *}$ & 1 & & & \\
\hline 3.Özerklik-Etki & 4,05 & 67 &, $374^{\star *}$ &, $428^{* *}$ & 1 & & \\
\hline 4.Duygusal Bağlılık & 3,65 & ,59 &, $469^{\star *}$ & , $144^{*}$ &, $394^{\star *}$ & 1 & \\
\hline $\begin{array}{l}\text { 5.Yapıcı } \\
\text { Çıkartma }\end{array}$ & 3,97 & 89 &, $285^{* *}$ &, $442^{* *}$ &, $484^{\star *}$ &, $363^{\star *}$ & 1 \\
\hline
\end{tabular}

Korelasyon analizi sonucu tespit edilen değerlere göre, araştırmanın bağımsız ve bağımlı değişkenleri arasında anlamlı düzeyde ve pozitif yönlü ilişkiler bulunmaktadır. Ayrıca ortalamalar çalışanların psikolojik güçlendirme algısının, duygusal bağlılığa sahip olma ve yapıcı ses çıkartma davranışı sergilme düzeylerinin pozitif yönde ortanın üzerinde olduğunu göstermektedir.

\subsection{Regresyon Analizi}

Araştırmanın bağımsız değişkeni olarak psikolojik güçlendirmenin, bağımlı değişkenler olarak belirlenen duygusal bağlııı ve yapıcı ses çıkartma davranışına olan etkisini incelemek amacıyla doğrusal (linear) regresyon analizi yapılmıştır.

Tablo 4: Psikolojik Güçlendirmenin, Duygusal Bağlılık ve Yapıcı Ses Çıkartma Davranışı Üzerindeki Etkisini İncelemeye Yönelik Regresyon Analizi

\begin{tabular}{llllll}
\hline Bağımsız Değişken: Psikolojik Güçlendirme & & & & \\
\hline Bağımlı Değişkenler & $\mathbf{R}^{\mathbf{2}}$ & $\mathbf{F}$ & $\boldsymbol{\beta}$ & $\mathbf{t}$ & $\mathbf{p}$ \\
Duygusal Bağılık & 20 & 52,129 &, 447 & 7,220 & $\mathbf{, 0 0 0}^{*}$ \\
Yapıcı Ses Çıkartma Davranışı & 27,8 & 80,530 &, 527 & 8,974 & $\mathbf{0 0 0}^{\star}$ \\
\hline
\end{tabular}

${ }^{*} p<0.01$ düzeyinde anlamlıdır.

Tablo 4'te yer alan bulgular incelendiğinde; duygusal bağlılık değişkeninin $\% 20$ 'sinin $\left(R^{2}=, 200\right)$ ve yapıcı ses çıkartma değişkeninin \%27,8'inin $\left(R^{2}=, 278\right)$ psikolojik güçlendirme değişkeni tarafından açıklandığı görülmektedir. Tespit edilen bulgular çerçevesinde, çalışanların psikolojik güçlendirme algılarının duygusal bağlılıklarını pozitif yönde $(\beta=, 447, p=, 000)$ ve anlamlı olarak etkilediği $\left(H_{1}\right)$ ile çalışanların psikolojik güçlendirme algılarının yapıcı ses çıkartma davranışlarını pozitif yönde $(\beta=, 527, p=, 000)$ ve anlamlı olarak etkilediği $\left(\mathrm{H}_{2}\right)$ hipotezleri kabul edilmektedir. 
Tablo 5: Psikolojik Güçlendirmenin Alt Boyutlarının Duygusal Bağlılık ve Yapıcı Ses Çıkartma Davranışı Üzerindeki Etkisini İncelemeye Yönelik Regresyon Analizi

\section{Bağımsız Değişken: Anlam}

\begin{tabular}{llllll}
\hline Bağımlı Değişkenler & $\mathbf{R}^{\mathbf{2}}$ & $\mathbf{F}$ & $\mathbf{B}$ & $\mathbf{t}$ & $\mathbf{p}$ \\
Duygusal Bağlılık & 22 & 58,934 &, 469 & 7,677 &, $\mathbf{0 0 0}^{\star}$ \\
& & & & & \\
Yapıcı Ses Çıkartma Davranışı & 08 & 18,525 &, 285 & 4,304 &, $\mathbf{0 0 0 *}$
\end{tabular}

Bağımsız Değişken: Yetkinlik

\begin{tabular}{llllll}
\hline Bağımlı Değişkenler & $\mathbf{R}^{\mathbf{2}}$ & $\mathbf{F}$ & $\boldsymbol{\beta}$ & $\mathbf{t}$ & $\mathbf{p}$ \\
Duygusal Bağlıık & 02 & 4,451 &, 144 & 2,110 & $\mathbf{0 3 6}^{\star \star}$ \\
Yapıcı Ses Çıkartma Davranışı & 19,5 & 50,612 &, 442 & 7,114 & $\mathbf{, 0 0 0 ^ { * }}$ \\
\hline
\end{tabular}

Bağımsız Değişken: Özerklik-Etki

\begin{tabular}{llllll}
\hline Bağımlı Değişkenler & $\mathbf{R}^{\mathbf{2}}$ & $\mathbf{F}$ & $\boldsymbol{\beta}$ & $\mathbf{t}$ & $\mathbf{p}$ \\
Duygusal Bağlılık & 15,5 & 38,321 &, 394 & 6,190 & $\mathbf{0 0 0}^{*}$ \\
Yapıcı Ses Çıkartma Davranışı & 23,4 & 63,972 &, 484 & 7,998 &, $\mathbf{0 0 0}^{*}$ \\
\hline
\end{tabular}

${ }^{*} p<0.01,{ }^{* *} p<0.05$ düzeyinde anlamlıdır.

Bağımsız değişken olarak psikolojik güçlendirmenin tüm alt boyutları ile bağımlı değişkenler olarak duygusal bağlılık ve yapıcı ses çıkartma davranışı üzerindeki etkisinin analiz sonuçları Tablo 5'te gösterilmektedir. Tespit edilen tüm sonuçlar, anlamlı ve pozitif bir yapı ortaya koymaktadır. Bu çerçevede ilgili sonuca göre, $\mathrm{H}_{1 \mathrm{a}}, \mathrm{H}_{1 \mathrm{~b}}$, $\mathrm{H}_{1 \mathrm{c}-\mathrm{d}}$ ve $\mathrm{H}_{2 \mathrm{a}}, \mathrm{H}_{2 \mathrm{~b}}, \mathrm{H}_{2 \mathrm{c}-\mathrm{d}}$ hipotezleri kabul edilmiştir. Ortaya çıkan sonuçlar bütünsel açıdan incelendiğinde, yapıcı ses çıkartma değişkeninin \%23,4'ünün $\left(R^{2}=, 234\right)$ psikolojik güçlendirme değişkeninin "özerklik-etki" boyutu tarafından, duygusal bağlılık değişkeninin \%22'sinin $\left(\mathrm{R}^{2}=, 220\right)$ ise psikolojik güçlendirme boyutunun "anlam" boyutu tarafından açıklandığı dikkat çekicidir.

Tablo 6'da bağımsız değişken olarak belirlenen duygusal bağlıı̆ın bağımlı değişken olarak yapıcı ses çıkartma davranışına olan etkisi incelenmiştir. Ortaya çıkan bulgular incelendiğinde; yapıcı ses çıkartma davranışının \%13.2'sinin $\left(R^{2}=, 132\right)$ duygusal bağııık değişkeni tarafından açıklandığı görülmektedir. Tespit edilen bulgular çerçevesinde, duygusal bağlılık, yapıcı ses çıkartma davranışını pozitif yönde $(\beta=, 363$, $p=, 000)$ ve anlamlı olarak etkilemektedir. Buna göre araştırmanın üçüncü hipotezi $\left(\mathrm{H}_{3}\right)$ kabul edilmektedir. 
Tablo 6: Duygusal Bağlılık ile Yapıcı Ses Çıkartma Davranışı Arasındaki İlişkiyi İncelemeye Yönelik Regresyon Analizi

\begin{tabular}{llllll}
\hline \multicolumn{2}{l}{ Bağımsız Değişken: Duygusal Bağııık } & & & & \\
\hline Bağımlı Değişken & $\mathbf{R}^{2}$ & $\mathbf{F}$ & $\boldsymbol{\beta}$ & $\mathbf{t}$ & $\mathbf{p}$ \\
Yapıcı Ses Çıkartma Davranışı & 13,2 & 31,784 &, 363 & 5,638 &, $000^{\star}$ \\
\hline
\end{tabular}

${ }^{*} p<0.01$ düzeyinde anlamlıdır.

\section{Sonuç ve Tartışma}

$\mathrm{Bu}$ araştırma, hizmet sektöründe psikolojik güçlendirme, duygusal bağlılık ve yapıcı ses çıkartma davranışı arasındaki ilişkilerin incelenmesi amacıyla yapılmıştır. KKTC'nin Girne bölgesinde yer alan beş yıldızlı otel işletmelerinin çeşitli departmanlarında görev yapan çalışanlardan toplanan verilerin analizi çerçevesinde, psikolojik güçlendirmenin duygusal bağlılık üzerinde etkili olduğu görülmüştür. Bu sonuca göre, araştırmanın örneklemi çerçevesinde çalışanların dahil oldukları işletmeye karşı duygusal bağlılıklarının oluşmasında psikolojik güçlendirme algıları, önemli bir değişken olarak ortaya çıkmaktadır. Duygusal bağlılığın oluşmasında özellikle, psikolojik güçlendirme değişkeninin alt boyutlarından "anlam" faktörünün daha etkili olduğu dikkat çekicidir. Tespit edilen sonuç genel olarak değerlendirildiğinde, otel işletmelerinin insan kaynakları yönetimine dikkat çekmekte fayda gözükmektedir. Çalışanın işini anlamlı bulması, doğru işte yer alması ile ilişkilidir. Bu noktada iş ve çalışan analizinin doğru yapılması sonucu doğru işe doğru çalışanın yerleştirilmesi (Pelit ve Ak, 2018) çalışanın duygusal bağlıı̆̆ının oluşmasında değer ifade etmektedir.

Araştırmadan elde edilen diğer bir sonuç, psikolojik güçlendirmenin tüm alt boyutları ile birlikte, çalışanın yapıcı ses çıkartma davranışı üzerinde etkili olduğudur. Elde edilen katsayılar incelendiğinde, psikolojik güçlendirmenin boyutlarından tek faktörde toplanan özerklik-etki boyutunun, yapıcı ses çıkartma davranışını daha fazla etkilediği sonucuna ulaşılmıştır. Çalışana iş süreci öncesi ilgili birimler tarafından gerekli açıklamaların yapılması sonrası çalışanın gereksiz müdahaleler altında kalmaması ve işini nasıl yürüteceğine dair kararları kendi kendine verebilmesi önemlidir. Akabinde çalışanın dahil olduğu bölüme karşı oluşacak olan etkili olduğu algısı, işletme lehine pek çok öneri ve bildirimde bulunma isteğini doğuracaktır (Raub ve Robert, 2012). Bu noktada departman yöneticilerinin, çalışanlara doğru zaman ve şekillerde bildirimde bulunması, çalışanların yaratıcı yönlerinin ve yapıcı önerilerinin ortaya çıkışını engellememesi adına önemlidir. Yönetim olgusuna dair mevcut klasik yaklaşımın yerini, ortak katılıma dayalı "çok aktörlü yönetim" olarak tanımlanan yeni bir yönetim anlayışı olan yönetişimin almaya başladığı unutulmamalıdır (Memduhoğlu, 2017).

Duygusal bağııı̆ın çalışanın yapıcı ses çıkartma davranışı üzerindeki etkililiği, araştırma kapsamında elde edilen diğer bir sonuçtur. Alanyazında örgütsel bağlıığın boyutlarından duygusal bağlıı̆̆ın, pozitif örgütsel çıktılar sağlaması itibariyle temel faktör olduğu belirtilmektedir (Payne ve Webber, 2006; Sturges ve diğ., 2005; Van Dyne ve Pierce, 2004). Çalışanların işletmeye karşı duyacakları duygusal bağlılıkta pek çok değişken etkin rol oynayabilir. Fakat bu araştırma doğrultusunda otel işletmelerinde çalışanların duygusal bağlılıkların sağlanması noktasında, psikolojik güçlendirmenin tüm alt boyutları itibariyle çalışanlara kazandırılması önemli görülmektedir. 
Hizmet sektörü içerisinde yer alan turizm, alt branşlarından biri olan otel işletmeleri çerçevesinde ilgili pazar diliminde önemli bir alanı oluşturmaktadır. Bölgelerde mevcut pek çok farklı otel işletmesi, sağladıkları unsurlara göre kategorize edilmektedir. Sınıflandırma kriterlerinde gerekli unsurları sağlayan otel işletmeleri, ilgili yıldız değerlendirmesine göre tanımlanmaktadır. Teorik olarak kazanılan yıldızların hizmetlere yansıması stratejik açıdan çok önemlidir. Bu doğrultuda işletmelerin sürdürülebilirliğinde ve rekabet üstünlüğü elde etmelerinde, taklit edilemez bir faktör olarak "çalışan" olgusuna dikkat çekmek, bu araştırmanın farkındalık yaratmak istediği ana temasıdır. İşletme, çalışan ve müşteri olarak konumlandırılan hizmet pazarlaması üçgeninde, hizmetlerin müşteri ile buluşturulması sürecinde, sürecin öncesi ve sonrasını kapsayan tüm dilimlerinde, çalışanların taşıdığı kritik rol, üzerinde düşünülmesi gereken pek çok olguya işaret etmektedir. Araştırma kapsamında elde edilen sonuçlardan yola çıkarak, otel işletmelerinin insan kaynakları ve birim yöneticilerine aşağıdaki öneriler sunulabilir.

- Turizm olayının yapısal özelliğinden dolayı, sektörde yer alacak çalışanların istihdamında, turizm mezuniyetinin aranacak temel kriterlerden biri olması, çalışanların hem işleriyle hem de işletmeleriyle bütünleşmelerinde profesyonel iş süreci açısından kolaylık sağlayabilir.

- Otel işletmelerinin birim yöneticileri ve insan kaynakları yöneticilerinin, çalışanları güçlendirmek adına ortak faaliyette bulunmaları, olumlu örgütsel çıktılar sağlanması açısından değer ifade edebilir.

- Çoğunlukla sektörel açıdan kısmen de kişisel gelişim konularında belli başlı zaman dilimlerinde eğitim ve seminerlerin düzenlenmesi, çalışan bağlılığının oluşması sürecine destek olabilir.

- Üst yönetimin sorumluluğundaki alanlar dışında, tüm operasyonel süreçlere dair, dahil olunan departman önceliğinde, çalışanın öneri ve görüşlerinin değerlendirildiği, açık şeffaf ve ortak katılıma dayalı bir sistemin oluşturulması, hizmet sağlayıcılar olarak çalışanlardan sağlanacak etkililik ve verimliliği arttırabilir.

Bu araştırmanın en önemli kısıtını evren oluşturmaktadır. Bu durum, elde edilen sonuçların genellenmesinde engel oluşturmaktadır. Gelecek çalışmalar için evrenin genişletilerek, turizm sektöründe yer alan diğer işletmelerin de dahil edilebileceği bir çalışma önerilebilir.

\section{Kaynakça}

Abdullah, A. G. K., Almadhoun, T. Z. ve Ling, Y. L. (2015), 'Psychological Empowerment, Job Satisfaction and Commitment Among Malaysian Secondary School Teachers' Asian Journal of Educational Research, 3 (3), ss. 34-42.

Agarwal, S., DeCarlo, T. E. ve Vyas, S. B. (1999), 'Leadership Behavior and Organizational Commitment: A Comparative Study of American and Indian Salespersons' Journal of International Business Studies, 30, ss. 727-753.

Akdemir, B. ve Çalış Duman, M. (2016), 'Duygusal Bağlılık ve İşgören Performası Arasındaki İlişkiye Yönelik Bir Araştırma' International Journal of Social Science, 46, ss. 343-357.

Allen, N. J. ve Meyer, J. P. (1990) 'The Measurement and Antecedents of Affective, Continuance and Normative Commitment to the Organization' Journal of Occupational Psychology, 63, ss. 1-18.

Bandura, A. (1977), 'Self-Efficacy: Toward a Unifying Theory of Behavioral Change' Psychological Review, 84 (2), ss. 91-215. 
Cohen, A. (2003), Multiple Commitments in The Workplace an Integrative Approach. New Jersey: Lawrence Erlbaum Associates Publishers.

Conger, J. A. ve Kanungo, R. N. (1988), 'The Empowerment Process: Integrating Theory and Practice' The Academy of Management Review, 13 (3), ss. 471-482.

Farndale, E., Van Ruiten, J., Kelliher, C. ve Hope-Hailey, V. (2011), 'The Influence of Perceived Employee Voice on Organisational Commitment: An Exchange Perspective' Human Resource Management, 50 (1), ss. 113-129.

Frazier, M. L. ve Fainshmidt, S. (2012), 'Voice Climate, Work Outcomes, and The Mediating Role of Psychological Empowerment A Multilevel Examination' Group \& Organization Management, 37 (6), ss. 691-715.

Fuller, J. B., Marler, L. E. ve Hester, K. (2006), 'Promoting Felt Responsibility for Constructive Change and Proactive Behavior: Exploring Aspects of an Elaborated Model of Work Design' Journal of Organizational Behavior, 27 (8), ss. $1089-1120$.

Hair, J. F., Anderson, R. E., Tatham, R. L. ve Black, W. C. (1998), Multivariate Data Analysis. New Jersey: Prentice-Hall Inc.

Hair, J. F., Ringle C. M. ve Sarstedt, M. (2011), 'PLS-SEM: Indeed a Silver Bullet' Journal of Marketing Theory and Practice, 19 (2), ss. 139-151.

Hashmi, M. S. ve Naqvi, I. H. (2012), 'Psychological Empowerment: A Key to Boost Organizational Commitment, Evidence from Banking Sector of Pakistan' International Journal of Human Resource Studies, 2 (2), ss. 132-141.

Işık, U. ve Yasım, Y. K. (2017), 'The Relation Between Psychological Reinforcement and Organizational Engagement of Hotel Employees' Hitit University Journal of Social Sciences Institute, 10 (2), ss. 1581-1594.

Jha, S. (2011), 'Influence of Psychological Empowerment on Affective, Normative and Continuance Commitment: A Study in the Indian IT Industry' Journal of Indian Business Research, 3 (4), ss. 263-282.

Karakaş, A. ve Serçek, S. (2014), 'Psikolojik Güçlendirme Algısının Örgütsel Bağlılığa Etkisi: Otel Çalışanları Üzerine Bir Araştırma' Seyahat ve Otel Iş̧letmeciliği Dergisi, 11 (2), ss. 90-107.

Kark, R., Shamir, B. ve Chen, G. (2003). 'The Two Faces of Transformational Leadership: Empowerment and Dependency' Journal of Applied Psychology, 88, ss. 246-255.

Kehoe, R. R. ve Wright, P.M. (2013), 'The Impact of High-Performance Human Resource Practices on Employees' Attitudes and Behaviors' Journal of Management, 39, ss. 366-391.

Kline, R. B. (2011), Principles and Practice of Structural Equation Modeling, 3. Baskı, New York: The Guilford Press.

Lapointe, É. ve Vandenberghe, C. (2018), 'Examination of the Relationships Between Servant Leadership, Organizational Commitment, and Voice and Antisocial Behaviors' Journal of Business Ethics, 148 (1), ss. 99-115.

LePine, J. A. ve Van Dyne, L. (1998), 'Predicting Voice Behavior in Work Groups' Journal of Applied Psychology, 83 (6), ss. 853-868.

Liang, J., Farh, C. I. C. and Farh, J. L. (2012), 'Psychological Antecedents of Promotive and Prohibitive Voice: A Two-Wave Examination' Academy Management, 55, ss. 71-92.

Macsinga, I., Sulea, C., Sârbescu, P., Fischmann, G. ve Dumitru, C. (2015), 'Engaged, Committed and Helpful Employees: The Role of Psychological Empowerment' The Journal of Psychology, 149 (3), ss. 263-276.

Maynes, T. D. ve Podsakoff, P. M. (2014), 'Speaking More Broadly: An Examination of The Nature, Antecedents and Consequences of an Expanded Set of Employee Voice Behaviors' Journal of Applied Psychology, 99 (1), ss. 87-112. 
Memduhoğlu, H. B. (2017), 'Yönetimde Yeni Yaklaşımlar' İçinde H.B. Memduhoğlu ve K. Yılmaz (Editörler), Yönetim Düşüncesinin Evrimi ve Yönetişim, ss. 2-42. Ankara: Pegem.

Meydan, C. H. ve Şeşen, H. (2011), Yapısal Eşitlik Modellemesi AMOS Uygulamaları, Ankara: Detay Yayıncılık.

Meyer, J. P. ve Allen, N. J. (1991), 'A Three-Component Conceptualization of Organizational Commitment' Human Resource Management Review, 1 (1), ss. 61-89.

Meyer, J. P. ve Allen, N. J. (1997), Commitment in the Workplace: Theory, Research and Application, Thousand Oaks, CA: SAGE Publications.

Meyer, J. P., Stanley, D. J., Herscovitch, L. ve Topolnytsky, L. (2002), 'Affective, Continuance and Normative Commitment to the Organization: A Meta-Analysis of Antecedents, Correlates and Consequences' Journal of Vocational Behavior, 61, ss. 20-52.

Morrison, E. W. (2011), 'Employee Voice Behavior: Integration and Directions for Future Research' Academy of Management Annals, 5 (1), ss. 373-412.

Ouyang, Y. Q., Zhou, W. B. ve Qu, H. (2015), 'The Impact of Psychological Empowerment and Organisational Commitment on Chinese Nurses' Job Satisfaction' Journal Contemporary Nurse, 50 (1), ss. 80-91.

Payne, S. C. ve Webber, S. S. (2006), 'Effects of Service Provider Attitudes and Employment Statues an Citizenship Behaviors and Customers' Attitudes and Loyalty Behavior' Journal of Applied Psychology, 91, ss. 365-378.

Pelit, E. ve Ak, S. (2018), 'İnsan Kaynakları Yönetimi İşlevi Olarak Personel Bulma, Seçme ve Personeli İşe Yerleştirme İle İlgili Sorunlar: Turizm İşletmeleri Örneğinde Teorik Bir İnceleme' İstanbul Aydın Üniversitesi Dergisi, 10 (2), ss. 39-74.

Purcell, J. (2014), 'Can Employee Voice and Participation Unlock Employee Engagement?' Insights: Melbourne Business and Economics, 15, ss. 23-29.

Raub, S. ve Robert, C. (2010), 'Differential Effects of Empowering Leadership on inRole and Extra-Role Employee Behaviors: Exploring The Role of Psychological Empowerment and Power Values' Human Relations, 63 (11), ss. 1743-1770.

Raub, S. ve Robert, C. (2012), 'Empowerment, Organizational Commitment and Voice Behavior in the Hospitality Industry: Evidence from a Multinational Sample' Cornell Hospitality Quarterly, 54 (2), ss. 136-148.

Rees, C., Alfes, K. ve Gatenby, M. (2013), 'Employee Voice and Engagement: Connections and Consequences' The International Journal of Human Resource Management, 24 (14), ss. 2780-2798.

Sigler, T. H. ve Pearson, C. M. (2000). 'Creating an Empowering Culture: Examining the Relationship Between Organizational Culture and Perceptions of Empowerment' Journal of Quality Management, 5, ss. 27-52.

Spreitzer, G. M. (1995), 'Psychological Empowerment in the Workplace: Dimensions, Measurement, and Validation' The Academy of Management Journal, 38 (5), ss. 1442-1465.

Stander, M. W. ve Rothmann, S. (2010), 'Psychological Empowerment, Job Insecurity and Employee Engagement' Journal of Industrial Psychology, 36, ss. 1-8.

Sturges, J., Conway, N., Guest, D. ve Liefooghe, A. (2005), 'Managing the Career Deal: The Psychological Contract as a Framework for Understanding Career Management, Organizational Commitment and Work Behavior' Journal of Organizational Behavior, 26, ss. 821-838.

Tabachnick, B. G. ve Fidell, L. S. (2013), Using Multivariate Statistics, 6. Baskı, Boston: Pearson. 
Tangirala, S. ve Ramanujam, R. (2012), 'Ask and You Shall Hear (But Not Always): Examining the Relationship Between Management Consultation and Employee Voice' Personnel Psychology, 65 (2), ss. 251-282.

Taylor, J. (2013), 'Goal Setting in The Australian Public Service: Effects on Psychological Empowerment and Organizational Citizenship Behavior' Public Administration Review, 73 (3), ss. 453-464.

Thomas, K. W. ve Velthouse, B. A. (1990), 'Cognitive Elements of Empowerment: An Interpretive Model of Intrinsic Task Motivation' The Academy of Management Review, 15 (4), ss. 666-681.

Wang, D., Gan, C. ve Wu, C. (2016), 'LMX and Employee Voice: A Moderated Mediation Model of Psychological Empowerment and Role Clarity' Personnel Review, 45 (3), ss. 605-615.

Wasti, S. A. (2005), 'Commitment Profiles: Combinations of Organizational Commitment Forms and Job Outcomes' Journal of Vocational Behavior, 67 (2), ss. 290-308.

Van Dyne, L., Ang, S. ve Botero, I. C. (2003), 'Conceptualizing Employee Silence and Employee Voice as Multidimensional Constructs' Journal of Management Studies, 40, ss. 1359-1392.

Van Dyne, L. ve Pierce, J. L. (2004), 'Psychological Ownership and Feelings of Possession: Three Field Studies Predicting Employee Attitudes and Organizational Citizenship Behavior' Journal of Organizational Behavior, 25, ss. 439-459. 